\title{
Multi-year temperature measurements of the middle atmosphere at Chatanika, Alaska $\left(65^{\circ} \mathrm{N}, 147^{\circ} \mathrm{W}\right)$
}

\author{
Brentha Thurairajah ${ }^{1}$, Richard L. Collins ${ }^{1}$, and Kohei Mizutani ${ }^{2}$ \\ ${ }^{1}$ Geophysical Institute and Department of Atmospheric Sciences, University of Alaska Fairbanks, \\ 903 Koyukuk Drive, Fairbanks, AK 99775-7320, USA \\ ${ }^{2}$ National Institute of Information and Communications Technology, 4-2-1 Nukui-kita, Koganei, Tokyo 184-8795, Japan
}

(Received March 7, 2008; Revised November 11, 2008; Accepted December 9, 2008; Online published July 27, 2009)

\begin{abstract}
Over an eight-year period (1997-2005) Rayleigh lidar temperature measurements of the stratosphere and mesosphere $(40-80 \mathrm{~km})$ have been made at Poker Flat Research Range, Chatanika, Alaska $\left(65^{\circ} \mathrm{N}, 147^{\circ} \mathrm{W}\right)$. The Rayleigh lidar measurements have been made between mid-August and mid-May. These measurements have yielded a total of approximately 904 hours of temperature measurements of the middle atmosphere over 116 nights. The seasonal evolution of the middle atmosphere shows an annual cycle with maximum in summer below $60 \mathrm{~km}$ and a reversal of the cycle with minimum in summer above $60 \mathrm{~km}$. The monthly mean stratopause has a highest temperature of $273 \mathrm{~K}$ at an altitude of $47.5 \mathrm{~km}$ in May and a lowest temperature of $243 \mathrm{~K}$ at an altitude of $54.7 \mathrm{~km}$ in January. However, nightly stratopause temperatures in January and December are sometimes warmer than those in May and August. An elevated stratopause $(>65 \mathrm{~km})$ is observed on 5 occasions in 41 observations in January and February. The Chatanika measurements are compared with five other Arctic data sets and models. The upper stratosphere at this site is slightly colder than the zonal mean as well as sites in Greenland and Scandinavia with the largest differences found in January. We discuss the wintertime temperatures in the upper stratosphere and lower mesosphere in terms of the position of the polar vortex and the increased occurrence of stratospheric warming events during the 1997-2005 observation period.
\end{abstract}

Key words: Circulation, mesosphere, stratosphere, Arctic, planetary waves, Rayleigh lidar.

\section{Introduction}

Measurements of middle atmosphere temperature support empirical studies of the climate and climate variability. Observations also constrain the behavior of numerical models. Since the mid-1980s, studies of trends in stratospheric temperatures have been recognized as a critical component in assessing changes in the stratospheric ozone layer (see reviews by Solomon, 1999; Ramaswamy et al., 2001; and references therein; WMO, 2007). Studies of coupling between the stratosphere and troposphere suggest that zonalmean circulation anomalies propagate downward from the upper stratosphere into the troposphere over the course of the winter, and that inclusion of the stratosphere in numerical prediction models can improve the accuracy of tropospheric forecasts (Boville, 1984; Baldwin and Dunkerton, 1999; Baldwin et al., 2007; and references therein). For example, Scaife et al. (2005) have used model simulations to study the link between stratospheric circulation and trends in the North Atlantic Oscillation (NAO) from the 1960 s to the $1990 \mathrm{~s}$. The results from this simulation showed that a strengthening of the stratospheric winter jet caused a strengthening of the tropospheric westerlies in the mid to high latitudes, a weakening of the westerlies at low latitudes, and an increase in the NAO index. These top-

Copyright (c) The Society of Geomagnetism and Earth, Planetary and Space Sciences (SGEPSS); The Seismological Society of Japan; The Volcanological Society of Japan; The Geodetic Society of Japan; The Japanese Society for Planetary Sciences; TERRAPUB ics have motivated the World Climate Research Program to investigate the effects of the middle atmosphere on climate, and support the project Stratospheric Processes And their Role in Climate (SPARC) (Pawson et al., 2000). The SPARC program has conducted an intercomparison study of contemporary and historical datasets to determine relative biases in middle atmosphere climatologies and has published a reference atlas of temperature and zonal-wind based on several of these datasets (SPARC, 2002; Randel et al., 2004).

Climatologies of the polar middle atmosphere have been challenging due to paucity of ground-based observations and seasonal limitations on space-based occultation methods. Furthermore, while the structure of the wintertime Antarctic middle atmosphere circulation is zonally symmetric, the structure of the wintertime Arctic middle atmosphere is zonally asymmetric (see comparative presentation of the structure of polar vortices in the northern and southern hemispheres by Schoeberl et al., 1992). The Arctic stratospheric vortex is primarily found in the eastern Arctic, while the Aleutian anti-cyclone is the dominant feature in the western Arctic. There is significant interaction between these systems during the winter that maintains a zonally asymmetric circulation (Harvey et al., 2002). During the winter, the structure of the Arctic stratosphere and mesosphere is also disturbed by stratospheric warming events (Labitzke, 1972). During major stratospheric warmings the zonal mean configuration of the circulation is dis- 
rupted (the stratospheric temperatures increase, the height of the stratopause changes, and zonal-mean zonal wind reverses). Up to the mid-1980s, major stratospheric warming events had been reported on an average every other year in the Arctic, while none had been reported in the Antarctic (see review by Andrews et al., 1987). No major warmings were reported in the Arctic from 1990-1998 while seven major warmings have been reported from 1999 to 2004 (Manney et al., 2005). The first reported Antarctic major stratospheric sudden warming occurred in 2002 (Allen et al., 2003) with an associated cooling in the mesosphere (Hernandez, 2003; Siskind et al., 2005). Thus, the definition of a zonally symmetric middle-atmosphere climatology for the Arctic is particularly challenging.

In this study we present multi-year measurements of the stratospheric and mesospheric temperature profile from a site in the western Arctic at Chatanika, Alaska $\left(65^{\circ} \mathrm{N}\right.$, $\left.147^{\circ} \mathrm{W}\right)$. These temperature measurements have been made with a Rayleigh lidar system that has been operated on an ongoing basis from November 1997 through April 2005. We present monthly mean temperature profiles for all months except June and July. We discuss the variability in these measurements. We compare these measurements with climatologies and seasonal data sets from groundbased measurements at other sites in the Arctic (Lübken and von Zahn, 1991; Lübken, 1999; Gerrard et al., 2000), the SPARC reference atlas (SPARC, 2002), the Extended Mass Spectrometer and ground-based Incoherent Scatter (MSISE-90) model (Hedin, 1991), and from satellite measurements (Clancy et al., 1994). We discuss the monthly temperatures in terms of zonal asymmetry, movement of the polar vortex, inter-annual variability of the Arctic middle atmosphere, and stratospheric warming events.

\section{Rayleigh Lidar Technique}

The National Institute of Information and Communications Technology (NICT) Rayleigh lidar was installed at Poker Flat Research Range (PFRR), Chatanika, Alaska in November 1997. NICT and the Geophysical Institute (GI) of the University of Alaska Fairbanks (UAF) jointly operate this Rayleigh lidar. The lidar observations were initiated during the Alaska Project, a ten-year international program of observations of the Arctic middle and upper atmosphere (Murayama et al., 2007).

The NICT Rayleigh lidar system consists of a Nd:YAG laser, a $0.6 \mathrm{~m}$ receiving telescope with a field-of-view of $1 \mathrm{mrad}$, a narrowband optical filter (bandwidth of either $1 \mathrm{~nm}$ or $0.3 \mathrm{~nm}$ FWHM), a photomultiplier tube, a photon counting detection system, and a computer-based data acquisition system (Mizutani et al., 2000; Collins et al., 2003). The lidar is a fixed zenith-pointing system. The laser operates at $532 \mathrm{~nm}$ with a pulse repetition rate of $20 \mathrm{pps}$, the laser pulse width is 7 ns FWHM, and the average laser power is $10 \mathrm{~W}$. The photon counts are integrated over $0.5 \mu$ s yielding a $75 \mathrm{~m}$ range sampling resolution. The raw photon count profiles are acquired every $50 \mathrm{~s}$ or $100 \mathrm{~s}$ representing the integrated echo from 1000 or 2000 laser pulses respectively. In the Rayleigh lidar technique like the searchlight technique (Elterman, 1951), we assume that the intensity profile of the scattered light is proportional to

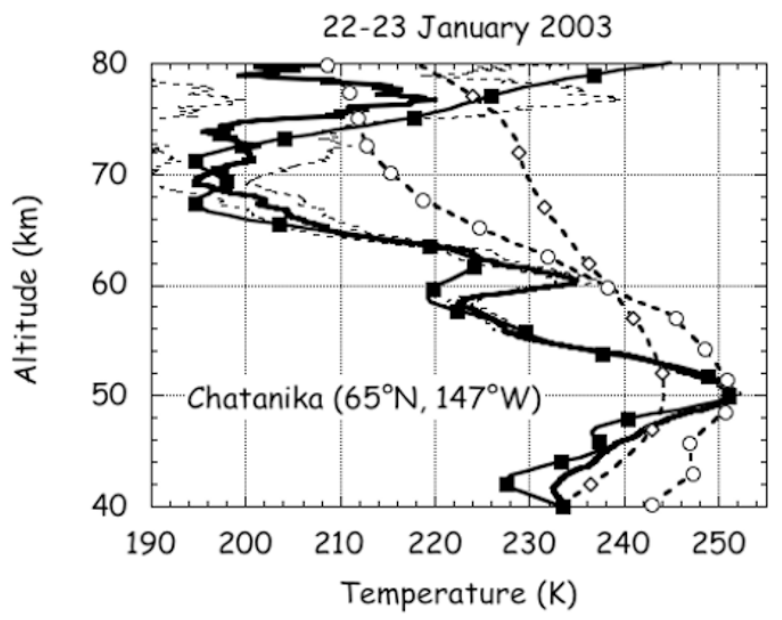

Fig. 1. Vertical temperature profile plotted as a function of altitude measured by Rayleigh lidar at PFRR, Chatanika, Alaska $\left(65^{\circ} \mathrm{N}, 147^{\circ} \mathrm{W}\right)$ for the period 2329-0130 LST on the night of 22-23 January 2003 LST (thick solid line). The uncertainty in the temperature profile is also plotted (thin dashed line). Temperature profile measured by SABER at $0030 \mathrm{LST}$ (solid line with solid square), reported by SPARC (dashed line with open circle) and MSISE-90 (dashed line with open diamond) are also plotted.

the density of the atmosphere, and the atmosphere is in hydrostatic equilibrium. The raw photon count signal can be described as a Poisson random variable (Pratt, 1969). We logarithmically smooth the raw photon count profile with a $2 \mathrm{~km}$ running average to reduce the uncertainty in the signal due to photon counting noise (see Papoulis and Pillai, 2002 for review of random variables and associated signal processing). We then correct the photon count profile for extinction due to Rayleigh scatter (Wang, 2003; Nadakuditi, 2005). We finally determine the Rayleigh lidar temperature profiles from the photon count profiles under standard inversion techniques by downward integration of the density profile with the assumption of an initial temperature at the upper altitude of $80 \mathrm{~km}$ (Leblanc et al., 1998). In this study we use the temperatures from the SPARC reference atlas to initialize the lidar temperature profiles. Thus the total uncertainty in the temperature estimate has two sources; the uncertainty in the initial temperature estimate (assumed to be $25 \mathrm{~K}$ ), and the statistical uncertainty in the raw photon count signal. The total uncertainty gives the accuracy in the absolute value of the temperature values while the statistical uncertainty in the raw lidar data gives the relative accuracy of the temperature in a given profile. The lidar signal increases with decreasing altitude and the lowest altitude is determined by the maximum photon counting rate (150 million counts per second) of the receiver. In these studies the lidar signal at $40 \mathrm{~km}$ is equivalent to $1-2$ million counts per second and the photon counting receiver records the lidar signal accurately (Donovan et al., 1993).

We plot an example of a Rayleigh lidar temperature measurement in Fig. 1. This is the temperature measured over a $2 \mathrm{~h}$ period on the night of 22-23 January 2003. We derived this lidar temperature profile from the lidar profile integrated over 63 individual raw photon count profiles (each representing the integrated signal of 2000 laser pulses) that 
were acquired between 2329 and 0130 LST (0829-1030 UT $(\mathrm{LST}=\mathrm{UT}-9 \mathrm{~h}))$. The initial temperature, from the SPARC reference atlas at $80 \mathrm{~km}$, contributes $100 \%$ of the temperature estimate at $80 \mathrm{~km}, 21 \%$ of the temperature estimate at $70 \mathrm{~km}, 4 \%$ at $60 \mathrm{~km}$, and $1 \%$ at $50 \mathrm{~km}$. The uncertainty in the temperature due to the initial temperature estimate decreases with decreasing altitude. An uncertainty of $10 \mathrm{~K}$ in the initial temperature at $80 \mathrm{~km}$ yields an error of $2.1 \mathrm{~K}$ at $70 \mathrm{~km}, 0.6 \mathrm{~K}$ at $60 \mathrm{~km}$, and $0.2 \mathrm{~K}$ at $50 \mathrm{~km}$. We plot the temperature profile bounded by the standard deviation of the total uncertainty due to the combination of the uncertainty in the photon count signal and the uncertainty in the initial temperature at $80 \mathrm{~km}$. The stratopause is at an altitude of $50.2 \mathrm{~km}$ and has a temperature of $251.6 \mathrm{~K}( \pm 0.7 \mathrm{~K})$. A mesospheric inversion layer (MIL) is at an altitude near $60 \mathrm{~km}$ with characteristics typical of MILs reported from PFRR (Cutler et al., 2001). This MIL has a maximum at $60.5 \mathrm{~km}$ with a temperature of $235.0 \mathrm{~K}( \pm 1.9 \mathrm{~K})$ and a minimum at $58.3 \mathrm{~km}$ with a temperature of $222.4 \mathrm{~K}( \pm 1.5 \mathrm{~K})$. The lapse rate on the topside $(61.0-62.0 \mathrm{~km})$ of the MIL is $-6.2 \mathrm{~K} / \mathrm{km}$. In summary the mesospheric inversion layer has a depth of $2.2 \mathrm{~km}$ and amplitude of $12.6 \mathrm{~K}( \pm 1.7 \mathrm{~K})$. There is a deep temperature minimum of $194.5 \mathrm{~K}( \pm 5.4 \mathrm{~K})$ in the mesosphere at $69.1 \mathrm{~km}$. There is also a shallow temperature minimum of $232.4 \mathrm{~K}( \pm 0.3 \mathrm{~K})$ in the stratosphere at $41.7 \mathrm{~km}$.

We also plot the temperature profile measured by the Sounding of the Atmosphere using Broadband Emission Radiometry (SABER) instrument aboard the Thermosphere Ionosphere Mesosphere Energetics Dynamics (TIMED) satellite (Russell et al., 1999; Mertens et al., 2001, 2004) in Fig. 1. The SABER temperature retrieval is Level 2A version 1.06. The SABER temperature measurement was made at $0030 \mathrm{LST}$ approximately $270 \mathrm{~km}$ northeast $\left(67^{\circ} \mathrm{N}\right.$, $\left.146^{\circ} \mathrm{W}\right)$ of the Rayleigh lidar. The SABER temperature profile is reported at a vertical resolution of $0.4 \mathrm{~km}$ and represents a measurement profile over $1.7^{\circ}$ of latitude and $6.9^{\circ}$ of longitude (Beaumont, 2007). We compare the lidar and $\mathrm{SABER}$ measurements at $1 \mathrm{~km}$ resolution. The temperature profiles measured by lidar and satellite show the same general structure; the stratopause is near $50 \mathrm{~km}$, there is a MIL near $60 \mathrm{~km}$, the deep temperature minimum near $70 \mathrm{~km}$, and the shallow temperature minimum in the stratosphere near $42 \mathrm{~km}$. The deep temperature minimum at $70 \mathrm{~km}$ is not the mesopause. The SABER profile shows a mesopause temperature minimum of $171 \mathrm{~K}$ at $102 \mathrm{~km}$ with temperatures steadily increasing above this altitude up to the highest measurement of $605 \mathrm{~K}$ at $155 \mathrm{~km}$. The mesopause altitude has a value typical of midwinter conditions when the mesopause is usually found at approximately $100 \mathrm{~km}$ as opposed to at $80 \mathrm{~km}$ in summer (e.g., Senft et al., 1994). The lidar temperature at the stratopause is $0.02 \mathrm{~K}$ warmer than the SABER stratopause temperature. The lidar measurement is on average warmer than the SABER measurement with an average difference of $2.6 \mathrm{~K}(4.3 \mathrm{~K} \mathrm{rms})$ between 40 and $70 \mathrm{~km}$. The largest difference of $12.5 \mathrm{~K}$ is found at 60 $\mathrm{km}$. The differences in the structure of the MIL measured by the lidar and SABER are within the spatial variations expected for MILs where the amplitudes of the inversions can vary by $10 \mathrm{~K}$ over hundreds of $\mathrm{km}$ (Leblanc et al., 1995).
We also plot the SPARC temperature profile for the month of January and the MSISE-90 temperature profile for local midnight on 22 January 2003 in Fig. 1. Clearly the lidar measurements indicate that the mesosphere is colder than both the SPARC and MSISE-90 profiles suggest. The fact that mesospheric temperatures in the Arctic are colder than those suggested by MSISE-90 has been noted in studies of noctilucent clouds at PFRR (Collins et al., 2003). We again compare the temperature profiles at $1 \mathrm{~km}$ resolution. The lidar temperature profile is on average $11.1 \mathrm{~K}$ less than the SPARC profile in the $40-70 \mathrm{~km}$ altitude region with a maximum difference of $21.4 \mathrm{~K}$ at $69 \mathrm{~km}$. The lidar temperature at the stratopause is $0.4 \mathrm{~K}$ warmer than the SPARC stratopause temperature. The lidar temperature profile is on average $10.1 \mathrm{~K}$ less than the MSISE-90 profile in the 40-70 $\mathrm{km}$ altitude region with a maximum difference of $34.8 \mathrm{~K}$ at $69 \mathrm{~km}$. The lidar temperature at the stratopause is $6.9 \mathrm{~K}$ warmer than the MSISE-90 stratopause temperature.

We have also compared the Rayleigh lidar temperature measurements at Chatanika with temperature retrievals from the Atmospheric Chemistry Experiment Fourier Transform Spectrometer (ACE-FTS) onboard the SCISAT1 satellite. Coincident measurements by both instruments report the same temperature structure with agreement in the measurement of the stratopause and MILs (Sica et al., 2008). The temperature differences between the lidar and ACE-FTS measurements are less than $5 \mathrm{~K}$ in the $40-70 \mathrm{~km}$ altitude region.

\section{Rayleigh Lidar Measurements}

Rayleigh lidar measurements of the upper stratosphere and mesosphere have been made in autumn, winter, and spring from November 1997 to April 2005. These observations made each year from August to May have yielded 116 individual nighttime measurements lasting between three and fifteen hours for a total of 904 hours of observations (Fig. 2). The average observation period lasted $7.8 \mathrm{~h}$. While Chatanika is below the Arctic Circle, the background light levels in summer twilight prevent measurements by this lidar in June and July.

We average the nightly mean profiles for each month to form the monthly mean profile. To study the temperature variability in the mean monthly middle atmosphere temper-

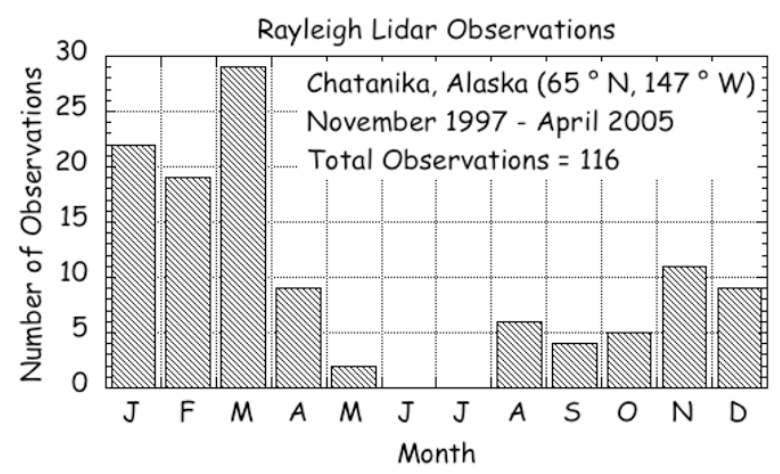

Fig. 2. Monthly distribution of 116 Rayleigh lidar measurements of nightly middle atmosphere temperature profiles at PFRR, Chatanika, Alaska $\left(65^{\circ} \mathrm{N}, 147^{\circ} \mathrm{W}\right)$. 

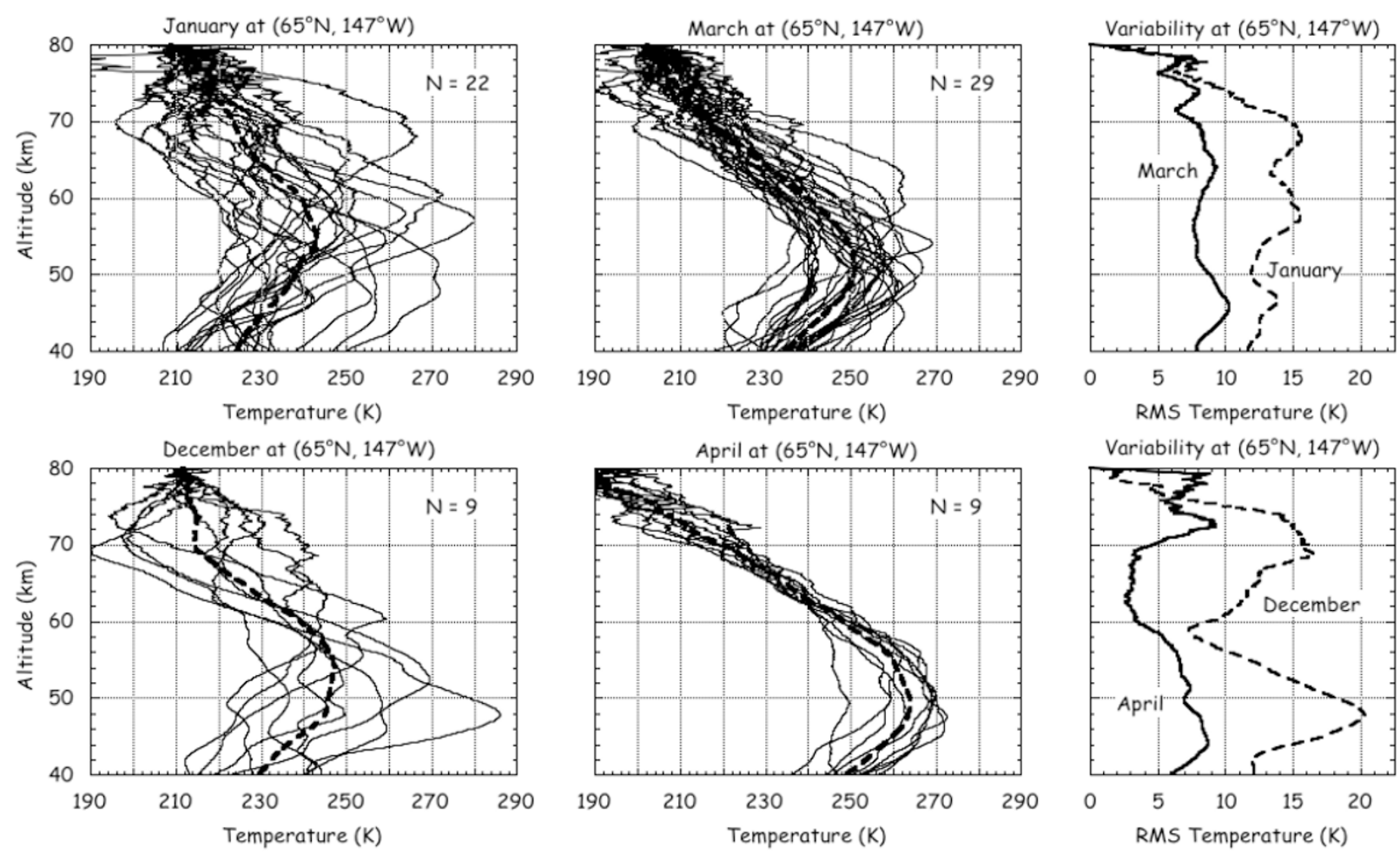

Fig. 3. Nightly temperature profiles as a function of altitude measured in January (upper left), March (upper center), December (lower left), and April (lower center) at PFRR, Chatanika, Alaska $\left(65^{\circ} \mathrm{N}, 147^{\circ} \mathrm{W}\right)$. The monthly average profile is also plotted (thick dashed line). The number of nightly profiles, $N$, is indicated on each panel. Sample standard deviation in nightly temperature profiles as a function of altitude measured in January and March (upper right), and December and April (lower right).

ature profiles we determine the sample standard deviation of the temperature measurements for each month at each altitude. We plot the individual and mean monthly profiles for January, March, December, and April in Fig. 3. The variability in winter (January and December) is much greater than in springtime (March and April). January and March have similar numbers of observations (22 and 29 respectively) and December and April have the same number of observations (nine each). We also plot the sample standard deviation of the nightly temperature measurements at each altitude in Fig. 3. The rms variability of the temperatures averaged over the $40-70 \mathrm{~km}$ altitude region is greater in December $(14 \mathrm{~K})$ and January $(14 \mathrm{~K})$ than in April $(6 \mathrm{~K})$ and March $(9 \mathrm{~K})$. The uncertainty in the sample mean temperatures is typically less than $5 \mathrm{~K}$.

We plot the monthly variation of the altitude and temperature of the stratopause in Fig. 4. We also plot the individual measurements for comparison. The monthly mean stratopause varies between altitudes of $47.5 \mathrm{~km}$ and $54.7 \mathrm{~km}$ and temperatures of 243 and $273 \mathrm{~K}$. The stratopause is highest in December and January and warmest in May. The individual nightly measurements show much greater variability than the monthly means. On a nightly basis the stratopause varies in altitude from $40.8 \mathrm{~km}$ to $71.1 \mathrm{~km}$ and in temperature from $230 \mathrm{~K}$ to $286 \mathrm{~K}$. The wintertime variability is clearly evident in Fig. 4 . The highest stratopause temperature was measured in early December while the lowest was measured in late January. The highest stratopause altitude was detected in early January while the lowest was detected in late February. We plot the monthly variation of the temperature at $45 \mathrm{~km}, 55 \mathrm{~km}$, and $65 \mathrm{~km}$ in Fig. 5, and the individual measurements for comparison. The monthly mean temperature at $45 \mathrm{~km}$ has a pronounced annual cycle with an average value of $249 \mathrm{~K}$, a maximum of $270 \mathrm{~K}$ in May, and a minimum of $231 \mathrm{~K}$ in January. The seasonal variation of $39.5 \mathrm{~K}$ is larger than the rms variation of $12.6 \mathrm{~K}$. The monthly mean temperature at $55 \mathrm{~km}$ has a less pronounced annual cycle with an average value of $251 \mathrm{~K}$, a maximum of $264 \mathrm{~K}$ in May, and a minimum of $240 \mathrm{~K}$ in February. The seasonal variation of $24.4 \mathrm{~K}$ is larger than the rms variation of $8.3 \mathrm{~K}$. The monthly mean temperature at $65 \mathrm{~km}$ has no clear annual cycle with an average value of $230 \mathrm{~K}$, a maximum of $235 \mathrm{~K}$, and a minimum of $222 \mathrm{~K}$. The annual variation of $12.9 \mathrm{~K}$ is larger than the rms variation of $4.2 \mathrm{~K}$. The wintertime nightly variability is again clearly evident at all altitudes. We see that nightly wintertime temperatures can be as warm as late spring and early fall temperatures at all altitudes.

We plot the monthly variation in the rms variability over the $40-70 \mathrm{~km}$ altitude range in Fig. 6. These rms values represent the rms of the standard deviations over the given altitude ranges. We subtract the variance due to measurement error from the total sample variance to give the geophysical variance. The yearly average value of the variability is $9 \mathrm{~K}$ with a maximum value of $14 \mathrm{~K}$ in December and a minimum of $4 \mathrm{~K}$ in September. The rms variability appears to have an annual variation with largest values in winter. There does not appear to be any systematic or significant variation of the variability with altitude. The annual variation does not appear to be function of the number of observations in 

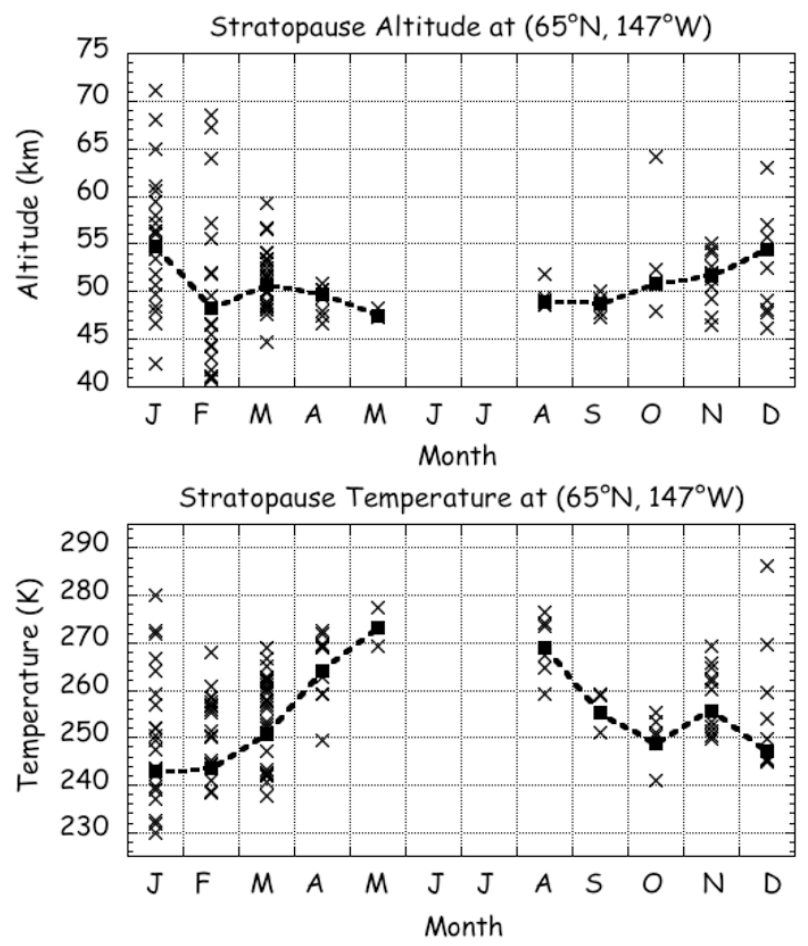

Fig. 4. Monthly variation of the stratopause altitude and temperature at PFRR, Chatanika, Alaska $\left(65^{\circ} \mathrm{N}, 147^{\circ} \mathrm{W}\right)$ measured by Rayleigh lidar. (Upper) Altitude of stratopause plotted as a function of month. (Lower) Temperature of stratopause plotted as a function of month. Individual nightly values $(x)$, monthly average profile (dashed line with closed square).

each month. The decrease through January, February and March and the increase through November and December occur when there are similar numbers of samples in each month (Fig. 2). The months with lowest number of samples (May through October) have smaller rms variability than would be expected from their sample statistics.

We present the monthly average temperature climatology of the upper stratosphere and mesosphere at PFRR, Chatanika, Alaska as a false color plot in altitude and time in Fig. 7. The pronounced annual cycle in temperatures, with a maximum in May and minimum in January, is clearly seen up to $\sim 60 \mathrm{~km}$. The highest temperature of $273 \mathrm{~K}$ is found at $47.5 \mathrm{~km}$ in May. The $47.5 \mathrm{~km}$ temperature has an annual range of $38 \mathrm{~K}$ with a minimum value of $235 \mathrm{~K}$ in January. The annual cycle is reversed at higher altitudes. The low temperatures in the upper stratosphere $(40-50 \mathrm{~km})$ in January are also evident. The location of the stratopause is plotted as a dashed line. The stratopause has a temperature of $273 \mathrm{~K}$ at an altitude of $47.5 \mathrm{~km}$ in May and a temperature of $243 \mathrm{~K}$ at an altitude of $54.7 \mathrm{~km}$ in January.

In Fig. 8 we plot the average vertical temperature profile measured at Chatanika for the month of January in 2004 and 2005. The January 2004 profile represents the average of three nights of observation on 5-6, 15-16, and 29-30 January. The three nightly profiles from 2004 correspond to three of the four highest stratopause altitudes recorded in January at Chatanika (Fig. 4 upper panel). The January 2005 profile represents the average of three nights of observation on 10-11, 18-19, and 27-28 January. We also plot
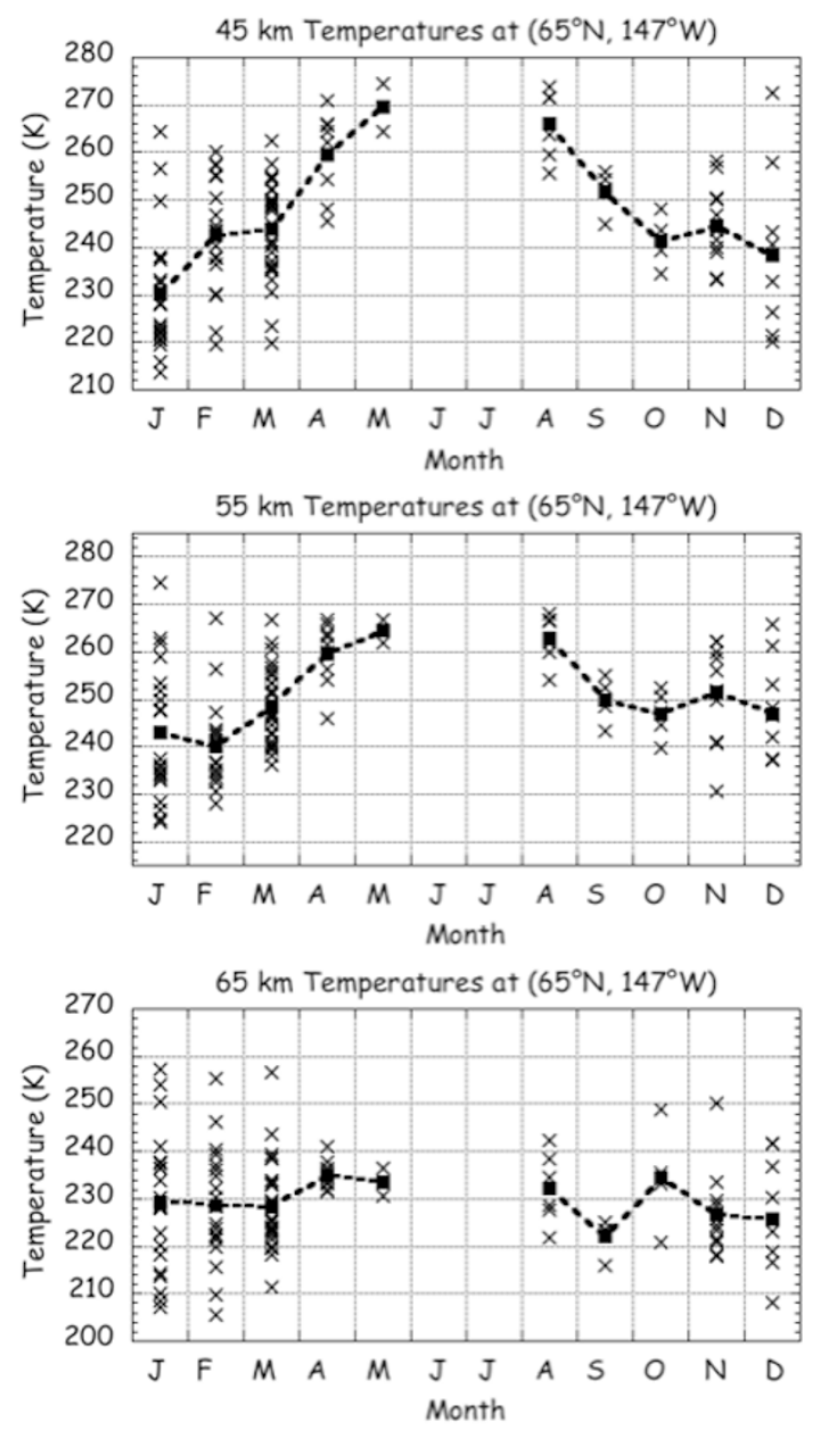

Fig. 5. Monthly variation of stratospheric and mesospheric temperatures measured by Rayleigh lidar at PFRR, Chatanika, Alaska $\left(65^{\circ} \mathrm{N}\right.$, $\left.147^{\circ} \mathrm{W}\right)$. The values from individual nightly measurements $(x)$ and monthly average profiles (dashed line with closed square) are plotted. (Upper) Temperature at $45 \mathrm{~km}$ plotted as a function of month. (Middle) Temperature at $55 \mathrm{~km}$ plotted as a function of month. (Lower) Temperature at $65 \mathrm{~km}$ plotted as a function of month.

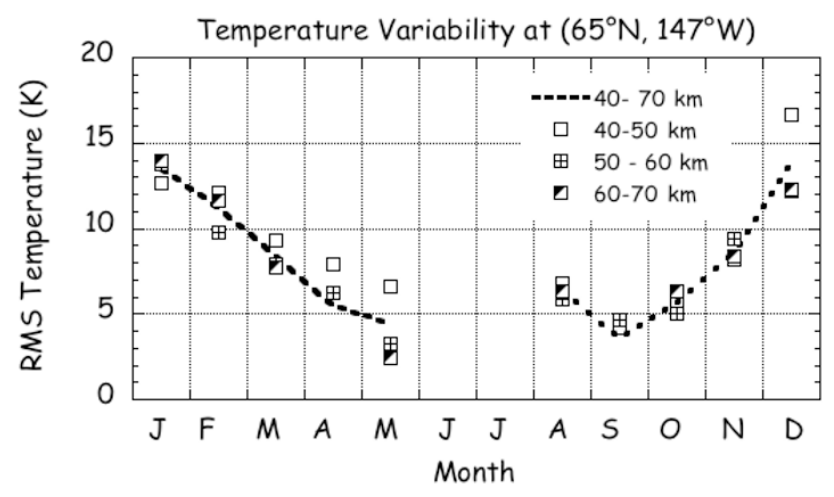

Fig. 6. Variation in rms temperature as a function of month at PFRR, Chatanika, Alaska $\left(65^{\circ} \mathrm{N}, 147^{\circ} \mathrm{W}\right)$. These rms temperatures are root mean-square averages of sample standard deviations over the $40-70 \mathrm{~km}$, $40-50 \mathrm{~km}, 50-60 \mathrm{~km}, 60-70 \mathrm{~km}$ altitude regions. The rms measurement error has been subtracted. 


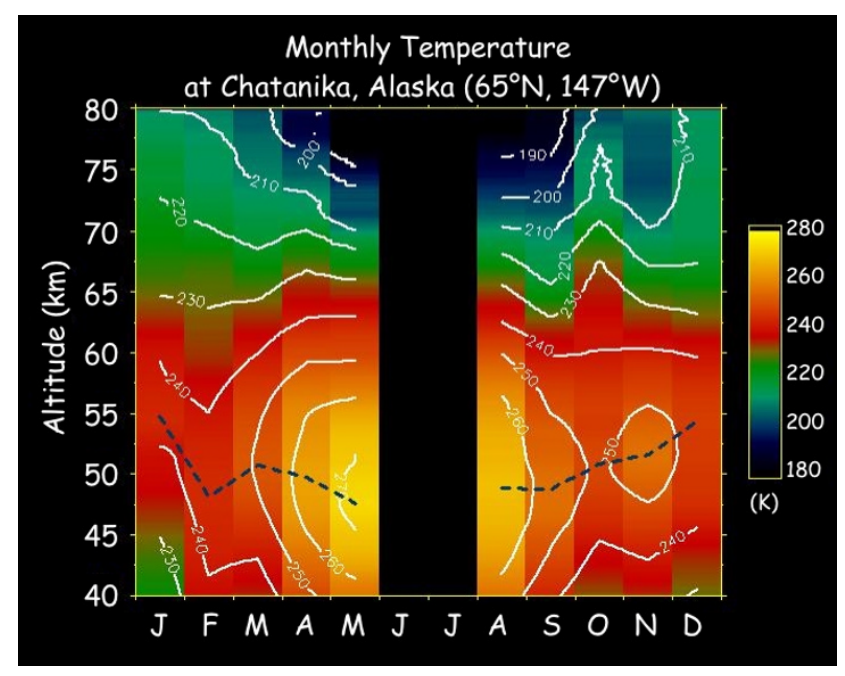

Fig. 7. False color plot of monthly mean temperature measured by Rayleigh lidar as a function of month and altitude at PFRR, Chatanika, Alaska $\left(65^{\circ} \mathrm{N}, 147^{\circ} \mathrm{W}\right)$. The stratopause altitude is plotted as a broken line. No measurements are reported for June and July.

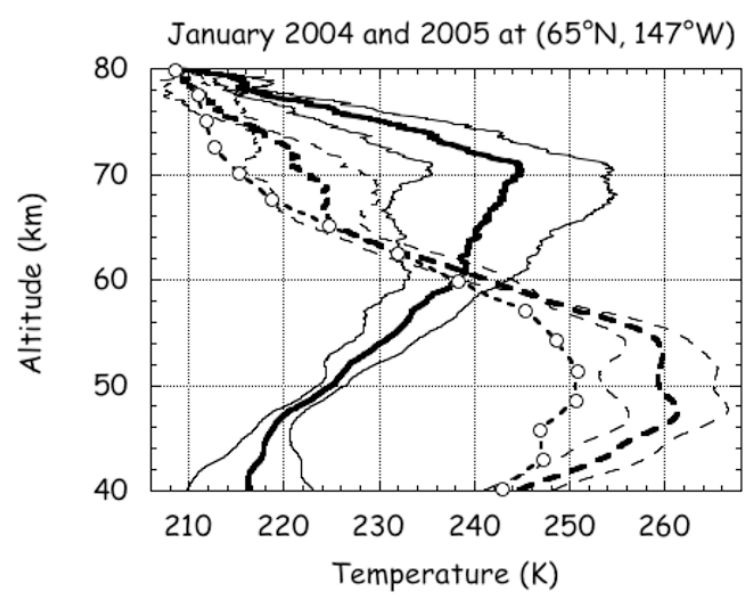

Fig. 8. Vertical temperature profile measured by Rayleigh lidar at PFRR, Chatanika Alaska $\left(65^{\circ} \mathrm{N}, 147^{\circ} \mathrm{W}\right)$ for January 2004 (thick solid line) and January 2005 (thick dashed line). The January 2004 profile represents the average of the three observations on the nights of 5-6, 15-16, and 29-30 January. The January 2005 profile represents the average of the three observations on the nights of 10-11, 18-19, and 27-28 January. The mean temperature plus and minus the sample uncertainty is also plotted (thin solid and thin dashed lines). The SPARC reference atlas profile for January is plotted for comparison (dashed line with open circle).

the average temperature profiles plus and minus the uncertainty in the sample mean value. The monthly average temperature profiles are significantly different. In 2005 the profile is more similar to the zonal mean profile at $64^{\circ} \mathrm{N}$ in the SPARC reference atlas (SPARC, 2002). In 2004 the profile shows an elevated stratopause and a colder stratosphere. In January 2004 the stratopause is located at $70.3 \mathrm{~km}$ with a temperature of $245.0 \mathrm{~K}$ while in 2005 the temperature is $221.8 \mathrm{~K}$ at $70.3 \mathrm{~km}$. In January 2005 the stratopause is located at $47.5 \mathrm{~km}$ with a temperature of $261.4 \mathrm{~K}$ while in 2004 the temperature is $220.4 \mathrm{~K}$ at $47.5 \mathrm{~km}$. The difference of $41.0 \mathrm{~K}$ at $47.5 \mathrm{~km}$ is significant as it is greater than the sum of the sample uncertainties in the average profiles and is 3.0 times greater than the rms variability at this altitude in the January data (Fig. 3). The difference of $23.2 \mathrm{~K}$ at $70.3 \mathrm{~km}$ is significant as it is greater than the sum of the sample uncertainties in the average profiles and is 1.6 times greater than the rms variability at this altitude in the January data (Fig. 3). The two high values $(67.2 \mathrm{~km}$ and $68.5 \mathrm{~km})$ of the stratopause altitude measured in February (Fig. 4, upper panel) and the single high value $(63.0 \mathrm{~km})$ in December are associated with temperature profiles that have an elevated stratopause with a colder stratosphere. The high value of the stratopause altitude in October $(64.2 \mathrm{~km})$ is associated with the presence of a large amplitude MIL in the mesosphere and there is no apparent cooling of the stratosphere.

\section{Comparison of Measurements from Chatanika} with Other Arctic Measurements and Models

We compare the Rayleigh lidar monthly average temperatures with temperatures reported by the SPARC (2002) reference atlas and single site Rayleigh lidar measurement from Kangerlussuaq, Greenland $\left(67^{\circ} \mathrm{N}, 51^{\circ} \mathrm{W}\right)$. We form the difference temperature by subtracting the SPARC temperature and Kangerlussuaq temperature from the temperature measured at Chatanika. We plot these differences in Fig. 9. Overall, Chatanika has a colder stratosphere and a slightly warmer mesosphere than the $64^{\circ} \mathrm{N}$ zonal mean temperatures reported by the SPARC reference atlas (upper panel). The largest difference is found in the stratosphere in January where the $42.3 \mathrm{~km}$ temperature is $20 \mathrm{~K}$ colder at Chatanika than in the zonal mean. In November the pattern is reversed where the $51.1 \mathrm{~km}$ temperature is $5 \mathrm{~K}$ warmer at Chatanika than in the zonal mean. Given a sample uncertainty in the mean monthly temperature profiles at Chatanika of less than $5 \mathrm{~K}$, significant temperature differences between Chatanika and the SPARC zonal mean are found in each month from August through April. The temperature measured at Chatanika is also generally lower than the temperature measured at Kangerlussuaq (lower panel). The largest difference is again found in the stratosphere in January where the $46.6 \mathrm{~km}$ temperature is $28 \mathrm{~K}$ lower at Chatanika than at Kangerlussuaq. The upper stratosphere and lower mesosphere in December are significantly cooler at Chatanika than at Kangerlussuaq, where the $64.0 \mathrm{~km}$ temperature is $24 \mathrm{~K}$ lower at Chatanika than at Kangerlussuaq. Given the sample uncertainty in the mean monthly temperature profiles at Chatanika, significant temperature differences between Chatanika and Kangerlussuaq are found in each month from September through March.

In Fig. 10 we plot the monthly variation of the altitude (upper panel) and temperature (lower panel) of the stratopause measured by the Rayleigh lidar at Chatanika with the stratopause altitude and temperature reported by other data sets and models (i.e., SPARC Reference atlas (SPARC, 2002), lidar measurements at Kangerlussuaq $\left(67^{\circ} \mathrm{N}, 51^{\circ} \mathrm{W}\right)($ Gerrard et al., 2000), falling spheres at Andoya $\left(69^{\circ} \mathrm{N}, 16^{\circ} \mathrm{E}\right)$ (Lübken, 1999$)$, lidar and in-situ density measurements at Andoya (Lübken and von Zahn, 1991), and MSISE-90 (Hedin, 1991)). The data sets show a variety of seasonal variations in the stratopause altitude from semiannual in the SPARC data to annual in the MSISE-90 data. The maximum values of the stratopause altitude are found 


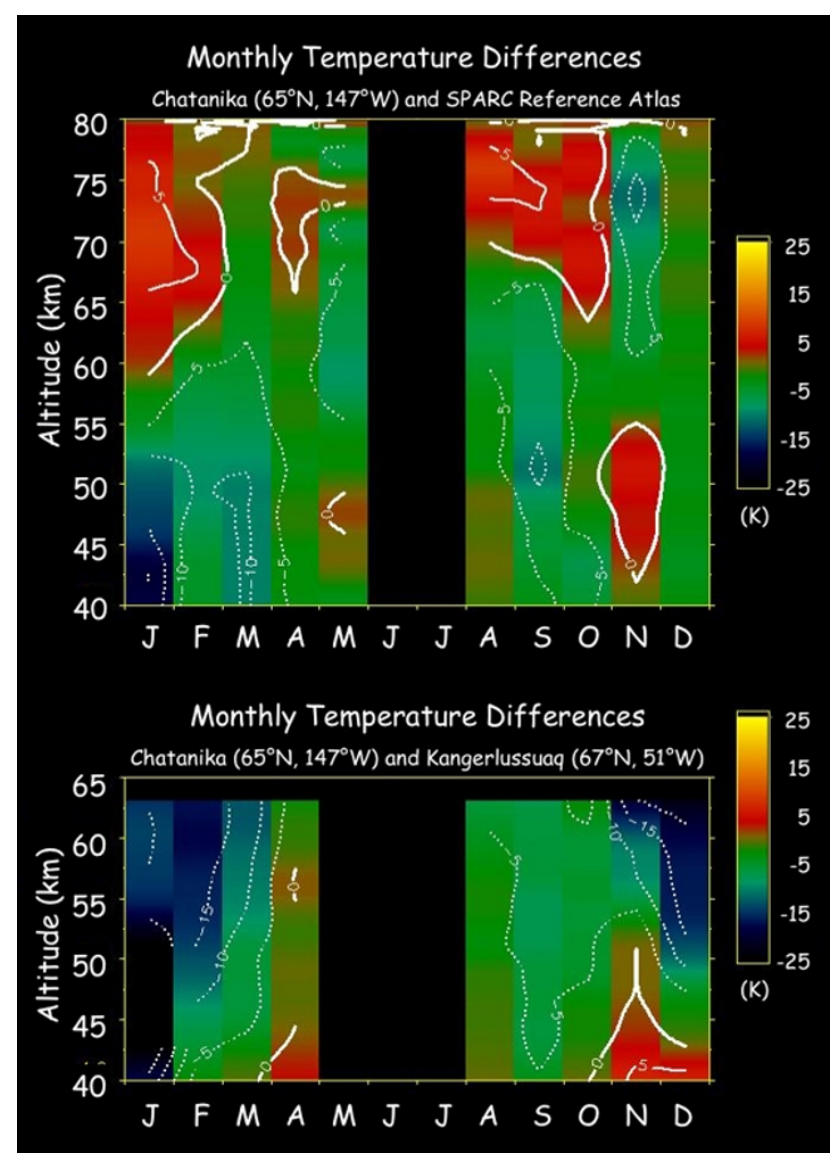

Fig. 9. Monthly temperature differences between the Rayleigh lidar measurements at PFRR, Chatanika, Alaska $\left(65^{\circ} \mathrm{N}, 147^{\circ} \mathrm{W}\right)$ and (upper) the SPARC reference atlas, and (lower) Rayleigh lidar measurements at Kangerlussuaq, Greenland $\left(67^{\circ} \mathrm{N}, 51^{\circ} \mathrm{W}\right)$. These difference temperatures are calculated by subtracting the temperatures of the SPARC reference atlas and the measurements at Kangerlussuaq from the temperature measurements at Chatanika.

in winter. The range of values in each month varies between $3.8 \mathrm{~km}$ in April and $6.7 \mathrm{~km}$ in March. The lidar measurements of the stratopause altitude at Chatanika generally fall inside the range of values reported by the different data sets. The one exception is in January when the Chatanika lidar measurements report a value of $54.7 \mathrm{~km}$ and all other data sets lie between $49.6 \mathrm{~km}$ and $51.4 \mathrm{~km}$. The data show an annual variation in the stratopause temperature, except for the measurements of Gerrard et al. (2000) and Lübken and von Zahn (1991) that show a secondary maximum in winter. All datasets show that the warmest stratopause temperatures occur in summer. The range of values in each month varies between $3.6 \mathrm{~K}$ in April and $21.1 \mathrm{~K}$ in January. The stratopause temperatures at Chatanika are generally cooler than the other measurements with the most significant differences in January, February, and March.

In Fig. 11 we plot the monthly variation of the temperature at $45 \mathrm{~km}$ (upper panel), $55 \mathrm{~km}$ (middle), and $65 \mathrm{~km}$ (lower panel) measured by the Rayleigh lidar at Chatanika with the temperatures reported by the other data sets and models in Fig. 10 and the $65^{\circ} \mathrm{N}$ zonal mean satellite measurements (Clancy et al., 1994). The various data sets show an annual variation in the temperatures with a summer maximum. This annual variation is most pronounced at $45 \mathrm{~km}$
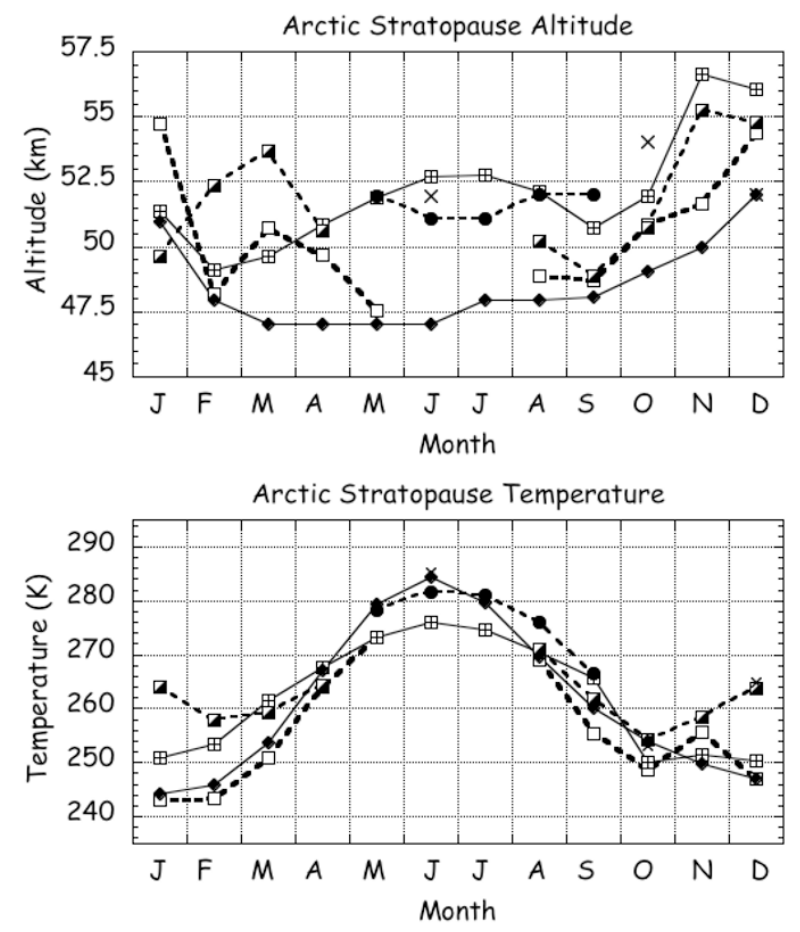

Fig. 10. Monthly variation of the stratopause in the Arctic. (Upper) Altitude of stratopause plotted as a function of month. (Lower) Temperature of stratopause plotted as a function of month. Rayleigh lidar measurements at Chatanika (dashed line with open square), SPARC Reference atlas (SPARC, 2002) (solid line with cross square), Gerrard et al. (2000) (dashed line with half open square), Lübken (1999) (dashed line with solid circle), Lübken and von Zahn (1991) (×), MSISE-90 (Hedin, 1991) (solid line with closed diamond).

and decreases with increasing altitude. At $45 \mathrm{~km}$, the largest range in temperatures is found in January when the temperature at Chatanika of $230.3 \mathrm{~K}$ is significantly lower (10.1$27.8 \mathrm{~K}$ ) than all other measurements. At $55 \mathrm{~km}$, the largest range is still found in January (even allowing for the unusually high temperatures reported by Lübken and von Zahn (1991)) when the temperature at Chatanika of $243.2 \mathrm{~K}$ is again the lowest but not significantly lower than MSISE-90. At $65 \mathrm{~km}$, the largest range of values is found in November with the temperature at Chatanika within the range of the other measurements. In general, we find that the lidar measurements at Chatanika report colder temperatures in the upper stratosphere in January, February, March, September, October, and December than those reported from other sites and the global mean.

\section{Discussion}

The current study is based on 116 nights of lidar measurements from a single site distributed between mid-August and mid-May from 1997 through 2005. The Rayleigh lidar measurements at Chatanika show a high degree of variability in the nightly temperature profile (Figs. 4 and 5). In considering the significance of the monthly averages we consider how the extent of the Chatanika data set compares with the other single-site studies; Lübken and von Zahn (1991) based their study on 180 days of temperature measurements made in all months except April, May and September over eleven years (1980-1990), Lübken (1999) 

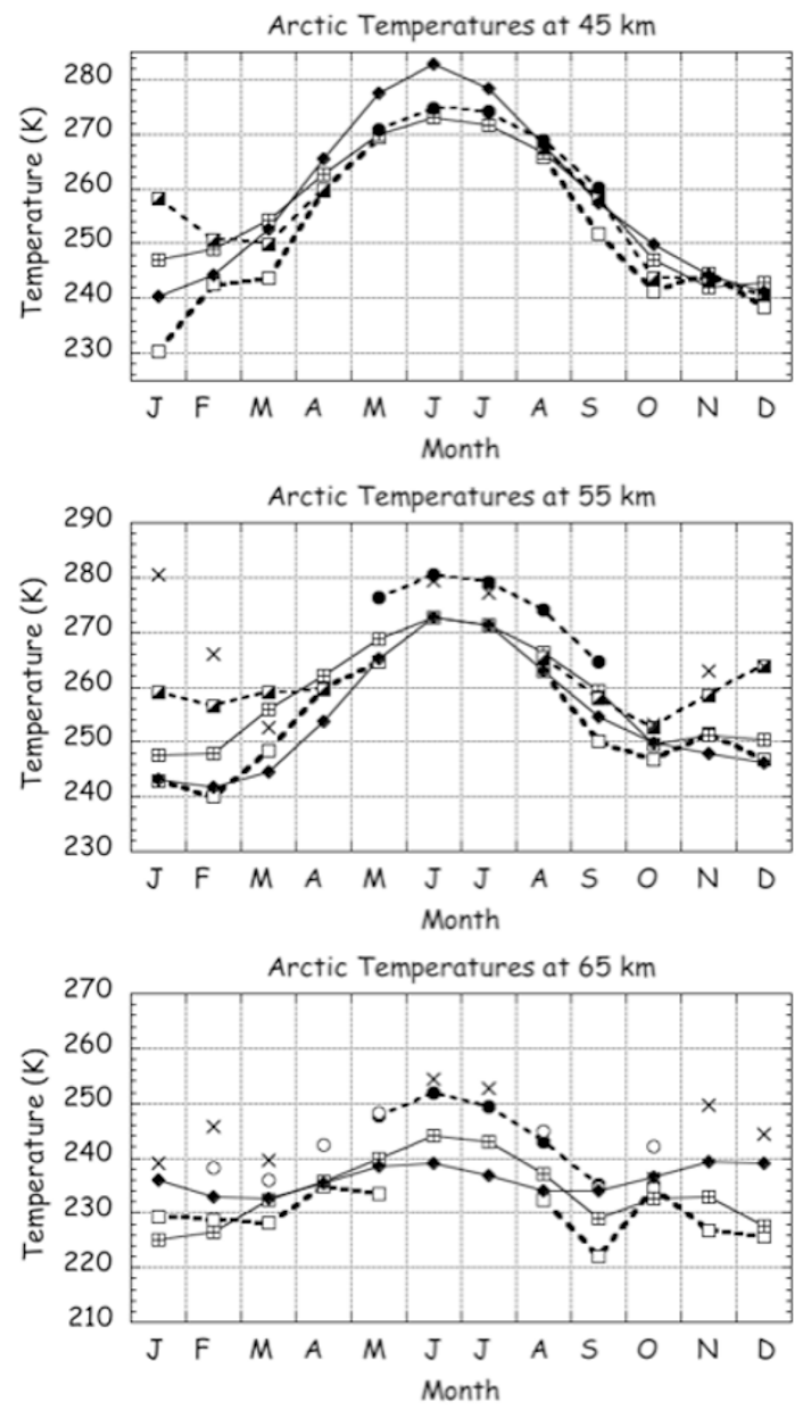

Fig. 11. Monthly variation of thermal structure of stratosphere and mesosphere in the Arctic. (Upper) Temperature at $45 \mathrm{~km}$ plottted as a function of month. (Middle) Temperature at $55 \mathrm{~km}$ plotted as a function of month. (Lower) Temperature at $65 \mathrm{~km}$ plotted as a function of month. See Fig. 10 for details. The $65 \mathrm{~km}$ plot includes data from Clancy et al. (1994) (open circle) in addition to the other data sets.

based his study on 89 measurements made between the end of April and end of September over eleven years (19871997), Gerrard et al. (2000) based their study on 179 measurements made in all months except June over four years (1995-1998). For example, the monthly average profiles for January are based on 22 profiles at Chatanika, 30 profiles at Kangerlussuaq (Gerrard et al., 2000), and 29 profiles at Andoya (Lübken and von Zahn, 1991). The difference in January, February and March between the upper stratosphere temperatures at Chatanika and the other measurements are statistically significant (Figs. 9, 10, and 11). We consider these differences in terms of the structure of the Arctic polar vortex and stratospheric warming events.

Duck et al. (2000) used Rayleigh lidar measurements at Eureka obtained during six wintertime campaigns from 1992-1993 to 1997-1998 to study the relationship between the thermal structure of the middle atmosphere and the location of the polar vortex. They compared measurements of middle atmosphere temperature profile at Eureka both when the vortex is overhead and when it is not. Duck et al. (2000) drew on 99 nights of temperature measurements to show that the upper stratosphere and lower mesosphere $(39-70 \mathrm{~km})$ is warmer and the lower stratosphere $(10$ $39 \mathrm{~km}$ ) is colder when the vortex is overhead. Conversely, when the vortex was not over Eureka they found that the upper stratosphere and lower mesosphere $(39-70 \mathrm{~km})$ is colder and the lower stratosphere $(10-39 \mathrm{~km})$ is warmer. The altitude of the stratopause remains relatively unchanged (49$53 \mathrm{~km}$ ) during these changes in vortex position. The change in temperature is approximately $20 \mathrm{~K}$ at $50 \mathrm{~km}, 30 \mathrm{~K}$ at $25 \mathrm{~km}$ and $0 \mathrm{~K}$ at $39 \mathrm{~km}$ (their Fig. 5). Gerrard et al. (2002) have studied the temperature structure of the Arctic by combining tropospheric and stratospheric analyses from the National Center for Environmental Prediction with Rayleigh lidar measurements at Andoya, Eureka, and Kangerlussuaq. Gerrard et al. (2002) report night-to-night changes in temperature of $20-40 \mathrm{~K}$ in the upper stratosphere and lower mesosphere associated with motion of the stratospheric vortex. The observations of colder temperatures in the upper stratosphere and lower mesosphere in December, January and February at Chatanika (Figs. 9 and 11) are consistent with the fact that Arctic polar vortex is predominantly found in the eastern Arctic closer to Andoya, Kangerlussuaq, and Eureka (e.g., Gerrard et al., 2000; Harvey et al., 2002). The fact that the differences between the single-site measurements at Chatanika and Kangerlussuaq are greater than between Chatanika and the zonal mean confirm this zonal asymmetry in the location of the polar vortex and the thermal structure of the Arctic middle atmosphere.

However, the observations in January 2004 and 2005 (Fig. 8) show that the colder middle atmosphere is associated with a large change in the stratopause altitude of $23 \mathrm{~km}$. These observations in 2004 contribute to our observation that the average stratopause in January at Chatanika is found at a higher altitude and has a colder temperature than in the other data sets (Fig. 10). Thus, the colder temperatures found in the upper stratosphere in Chatanika in January relative to the zonal mean and Kangerlussuaq (Fig. 9) is due to factors other than the position of the polar vortex position. Manney et al. (2005) noted the fact that recent winters have been warmer in the Arctic lower stratosphere. During these winters, major stratospheric warmings were common ( 7 in 6 years) resulting in unusually high temperatures in the lower stratosphere and lower temperatures in the upper stratosphere and mesosphere. Manney et al. (2005) restricted their study to meteorological analyses that were capped at $1 \mathrm{hPa}(\sim 50 \mathrm{~km})$. Manney et al. (2008a) report satellite and lidar measurements of stratospheric and mesospheric temperatures over Eureka in early 2004, 2005 and 2006. Their observations show that following major stratospheric warmings in 2004 and 2006 the vortex breaks down throughout the stratosphere, there is a complete disappearance of the warm stratopause, and subsequent reformation of a cool stratopause near $75 \mathrm{~km}$. The elevated stratopause then descends and warms over a several week period. Siskind et al. (2007) use a global circulation model to show that the observations in 2006 are consistent with a circulation where the gravity-wave driven 
meridional circulation has been disrupted (recalling the earlier work on the separated polar winter stratopause of Hitchman et al. (1989)). As a result the lower stratosphere radiatively cooled and the stratopause appears near $0.01 \mathrm{hPa}$ $(\sim 78 \mathrm{~km})$ with a temperature of approximately $235 \mathrm{~K}$ in the daily zonal mean at $65^{\circ} \mathrm{N}$. Manney et al. (2008b) have subsequently documented the life-cycle of this 2006 major stratospheric warming event with data from the Microwave Limb Sounder and SABER over the whole northern hemisphere. They show that over a three-week period following the major warming there is a complete disappearance of the warm stratopause followed by reformation of a cooler stratopause near $75 \mathrm{~km}$ that warms and descends to the original pre-warming altitude. Furthermore Manney et al. (2008b) show that the elevated stratopause in 2006 varies with longitude and extends over about half the polar region. The fact that the mean monthly temperature profile for January 2004 shows an elevated stratopause is consistent with the fact that the disruption of the stratosphere following a major stratospheric sudden warming can last nearly a month.

The other Arctic observations come from earlier time periods; the SPARC atlas represents measurements from 1992-1997 (SPARC, 2002), Gerrard et al. (2000) present data from 1995-1998, Lübken (1999) presents data from 1987-1997, Lübken and von Zahn (1991) present data from 1980-1990, the MSISE-90 model is largely based on data from the 1960s through the 1980s (Hedin, 1991), and Clancy et al. (1994) present data from 1982-1986. Thus, the thermal structure associated with the colder temperatures in the upper stratosphere in January at Chatanika may reflect the contribution of years when the upper stratosphere and lower mesosphere were colder than expected due to the increased frequency of stratospheric warmings in the 19972005 period.

\section{Conclusions}

We have used an eight-year Rayleigh lidar temperature data over Chatanika, Alaska to document the temperature structure of the stratosphere and mesosphere in the western Arctic. Individual lidar measurements have been compared with satellite measurements and found in good agreement. The monthly mean lidar measurements at Chatanika show that the seasonal variations in the monthly mean temperatures follow the expected variations with an annual cycle with summer maximum and winter minimum $(273 \mathrm{~K}$ at $47.5 \mathrm{~km}$ in May and $243 \mathrm{~K}$ at $54.7 \mathrm{~km}$ in January) below $60 \mathrm{~km}$ and an annual cycle with winter maximum and summer minimum above $60 \mathrm{~km}$. However, the Chatanika measurements reveal an upper stratosphere that is slightly colder than that reported from observations at sites in Scandinavia and Greenland and in satellite measurements of the zonal mean. The study highlights the high degree of variability in the wintertime middle atmosphere when the stratopause is sometimes warmer than in May and August.

The colder January and February temperatures are associated with an elevated stratopause $(>65 \mathrm{~km})$ that is observed on 5 occasions in 41 observations in January and February. The measurements in January are significantly colder than reported from eastern Arctic sites and in the zonal mean. While this difference is consistent with the influence of the polar vortex in the eastern Arctic, we conclude that the significantly lower temperatures in the upper stratosphere in January at Chatanika may reflect the contribution of years when the upper stratosphere and lower mesosphere were colder than expected due to the increased frequency of stratospheric sudden warmings in the 19972005 period. A more comprehensive analysis of the contribution of the position of the polar vortex and stratospheric warming events to the observed thermal structure of the Arctic middle atmosphere would require a higher frequency of observations uniformly distributed across the Arctic. Such a detailed pan-Arctic multiyear analysis could be conducted using SABER data for the period starting in 2002.

Acknowledgments. The authors thank the following University of Alaska students for their assistance in making the ongoing lidar observations; J. Breese, L. Cutler, T. Hao, S. Nadakuditi, K. Nowicki, M. Peshave, T. Stern, L. Su, W. Wang, and J. Yue. The authors thank K. Sakanoi for her assistance with the spring 2003 measurements. The authors acknowledge the SABER science and data processing teams for providing the SABER data presented in the paper. The authors thank R. S. Lieberman for helpful discussion and comments. The authors thank the staff at PFRR for their ongoing support of the lidar program. The authors acknowledge support from the United States National Science Foundation, under grants ARC 06-32387 and ATM 06-40340, and from the United States Airforce and Navy under the DMSP SSMIS Cal/Val Program, under contract N00173-01-1-G901. PFRR is a rocket range operated by GI-UAF with support from NASA.

\section{References}

Allen, D. R., R. M. Bevilacqua, G. E. Nedoluha, C. E. Randall, and G. L. Manney, Unusual stratospheric transport and mixing during the 2002 Antarctic winter, Geophys. Res. Lett., 30(12), 1599, doi:10. 1029/2003GL017117, 2003.

Andrews, D. G., J. R. Holton, and C. B. Leovy, Middle atmosphere dynamics, 489 pp., Academic Press Inc., New York, 1987.

Baldwin, M. P. and T. J. Dunkerton, Propagation of Arctic oscillation from the stratosphere to the troposphere, J. Geophys. Res., 104(D24), 3093730946, 1999.

Baldwin, M. P., M. Dameris, and T. G. Shepherd, How will the stratosphere affect climate change, Science, 316, 1576-1577, 2007.

Beaumont, K., SABER: Sounding of the atmosphere using broadband emission radiometry, http://saber.gats-inc.com/, accessed June, 2007.

Boville, B. A., The influence of the polar night jet on the tropospheric circulation in a GCM, J. Atmos. Sci., 41(7), 1132-1142, 1984.

Clancy, R. T., D. W. Rusch, and M. T. Callan, Temperature minima in the average thermal structure of the middle mesosphere $(70-80 \mathrm{~km})$ from analysis of 40- to 92-km SME global temperature profiles, J. Geophys. Res., 99(D9), 190001-19020, 1994.

Collins, R. L., M. C. Kelley, M. J. Nicolls, C. Ramos, T. Hou, T. E. Stern, K. Mizutani, and T. Itabe, Simultaneous lidar observations of a noctilucent cloud and an internal wave in the polar mesosphere, $J$. Geophys. Res., 108(D8), 8435, doi:10.1029/2002JD002427, 2003.

Cutler, L. J., R. L. Collins, K. Mizutani, and T. Itabe, Rayleigh lidar observations of mesospheric inversion layers at Poker Flat, Alaska $\left(65^{\circ} \mathrm{N}\right.$, $\left.147^{\circ} \mathrm{W}\right)$, Geophys. Res. Lett., 28(8), 1467-1470, 2001.

Donovan, D. P., J. A. Whiteway, and A. I. Carswell, Correction for nonlinear photon-counting effects in lidar systems, App. Opt., 32(33), 6742$6753,1993$.

Duck, T. J., J. A. Whiteway, and A. I. Carswell, A detailed record of high Arctic middle atmospheric temperatures, J. Geophys. Res., 105(D18), 22,909-22,918, 2000.

Elterman, L., The measurement of stratospheric density distribution with the searchlight technique, J. Geophys. Res., 56(4), 509-520, 1951.

Gerrard, A. J., T. J. Kane, and J. Thayer, Year-round temperature and wave measurements of the Arctic middle atmosphere for 1995-1998, in Atmospheric science across the stratopause, edited by D. E. Siskind, 
S. D. Eckermann, and M. E. Summers, AGU Monograph, 123, 2000. Gerrard, A. J., T. J. Kane, J. P. Thayer, T. J. Duck, J. A. Whiteway, and J. Fiedler, Synoptic scale study of the Arctic polar vortex's influence on the middle atmosphere, 1, Observations, J. Geophys. Res., 107(D16), 4276, doi:10.1029/2001JD000681, 2002.

Harvey, V. L., R. B. Pierce, T. D. Fairlie, and M. H. Hitchman, A climatology of stratospheric polar vortices and anticyclones, J. Geophys. Res., 107(D20), 4442, doi:10.1029/2001JD001471, 2002.

Hedin, A. E., Extension of the MSIS thermospheric model into the middle and lower atmosphere, J. Geophys. Res., 96(A2), 1159, 1991.

Hernandez, G., Climatology of the upper mesosphere temperature above South Pole $\left(90^{\circ} \mathrm{S}\right)$ : Mesospheric cooling in 2002, Geophys. Res. Lett., 30(10), 1535, doi:10.1029/2003GL016887, 2003.

Hitchman, M. H., J. C. Gille, C. D. Rogers, and G. Brasseur, The separated polar winter stratopause: A gravity wave driven climatological feature, J. Atmos. Sci., 46(3), 1989

Labitzke, K., Temperature changes in the mesosphere and stratosphere connected with circulation changes in winter, J. Atmos. Sci., 29(4), 756$766,1972$.

Leblanc, T., A. Hauchecorne, M.-L. Chanin, C. Rogers, F. Taylor, and N. Livesey, Mesospheric temperature inversions as seen by ISAMS in December 2001, Geophys. Res. Lett., 22(12), 1485-1488, 1995.

Leblanc, T., I. S. McDermid, A. Hauchecorne, and P. Keckhut, Evaluation of optimization of lidar temperature analysis algorithms using simulated data, J. Geophys. Res., 103(D6), 6177-6187, 1998.

Lübken, F.-J., Thermal structure of the Arctic summer mesosphere, $J$. Geophys. Res., 104(D8), 9135-9149, 1999.

Lübken, F.-J. and U. von Zahn, Thermal structure of the mesopause region at polar latitudes, J. Geophys. Res., 96(D11), 20841-20857, 1991.

Manney, G. L., K. Kruger, J. L. Sabutis, S. A. Sena, and S. Pawson, The remarkable 2003-2004 winter and other recent winters in the Arctic stratosphere since the late 1990s, J. Geophys. Res., 110, D04107, doi:10. 1029/2004JD005367, 2005.

Manney, G. L., W. H. Daffer, K. B. Strawbridge, K. A. Walker, C. D. Boone, P. F. Bernath, T. Kerzenmacher, M. J. Schwartz, K. Strong, R. J. Sica, K. Kruger, H. C. Pumphrey, L. Froidevaux, A. Lambert, M. L. Santee, N. J. Livesey, E. E. Remsberg, M. G. Mlynczak, and J. R. Russell III, The high Arctic in extreme winters: vortex, temperature, and MLS and ACE-FTS trace gas evolution, Atmos. Chem. Phys., 8, 505-522, 2008a.

Manney, G. L., K. Krueger, S. Pawson, K. Minschwaner, M. J. Schwartz, W. Daffer, N. J. Livesey, M. G. Mlynczak, E. Remsberg, J. M. Russell, and J. W. Waters, The evolution of the stratopause during the 2006 major warming: Satellite data and assimilated meteorological analyses, J. Geophys. Res., doi:10.1029/2007JD009097, 2008b (in press).

Mertens, C. J., M. G. Mlynczak, M. Lopez-Puertas, P. P. Wintersteiner, R. H. Picard, J. R. Winick, L. L. Gordley, and J. M. Russell III, Retrieval of mesospheric and lower thermospheric kinetic temperature from measurements of CO2 $15 \mathrm{~mm}$ Earth limb emission under non-LTE conditions, Geophys. Res. Lett., 28(7), 1391-1394, 2001.

Mertens, C. J., F. J. Schmidlin, R. A. Goldberg, E. E. Remsberg, W. D. Pesnell, J. M. Russell III, M. G. Mlynczak, M. Lopez-Puertas, P. P. Wintersteiner, R. H. Picard, J. R. Winick, and L. L. Gordley, SABER observations of mesospheric temperatures and comparisons with falling sphere measurements taken during the 2002 summer MaCWAVE campaign, Geophys. Res. Lett., 31(3), L03105, doi:10.1029/2003GL018605, 2004.

Mizutani, K., T. Itabe, M. Yasui, T. Aoki, Y. Murayama, and R. L. Collins, Rayleigh and Rayleigh Doppler lidars for the observations of the Arctic middle atmosphere, IEICE Trans. Fundam. Electron. Commun. Comput. Sci., E83-B, 2003, 2000

Murayama, Y., M. Ishii, M. Kubota, M. Hirotaka, K. Mizutani, S. Ochiai, Y. Kasai, S. Kawamaura, Y. Tanaka, H. Masuko, T. Iguchi, H. Kumagai, T. Kikuchi, K. Sata, R. L. Collins, B. J. Watkins, M. Conde, W. B. Bristow, and R. W. Smith, Comprehensive Arctic atmosphere observing system and observed results for system performance demonstration, $J$. Nat. Instit. Info. Comms. Tech, 54(1/2), 5-16, 2007.

Nadakuditi, S., Spectral estimation of wave-driven fluctuations in Rayleigh lidar temperature measurements, MS Thesis, University of Alaska Fairbanks, 2005.
Papoulis, A. and S. U. Pillai, Probability, Random Variables, and Stochastic Processes, fourth edition, 852 pp., McGraw-Hill, New York, 2002.

Pawson, S., K. Kodera, K. Hamilton, T. G. Shepherd, S. R. Beagley, B. A. Boville, J. D. Farrara, T. D. A. Fairlie, A. Kitoh, W. A. Lahoz, U. Langematz, E. Manzini, D. H. Rind, A. A. Scaife, K. Shibata, P. Simon, R. Swinbank, L. Takacs, R. J. Wilson, J. A. Al-Saadi, M. Amodei, M. Chiba, L. Coy, J. de Grandpré, R. S. Eckman, N. Fiorino, W. L. Grose, H. Koide, J. N. Koshyk, D. Li, J. Lerner, J. D. Mahlman, N. A. McFarlane, C. R. Mechoso, A. Molod, A. O’Neill, R. B. Pierce, W. J. Randel, R. B. Rood, and F. Wu, The GCM-reality intercomparison project for SPARC (GRIPS): Scientific issues and initial results, Bull. Am. Meteor. Soc., 81(4), 781-796, 2000.

Pratt, W. K., Laser communications systems, 271 pp., Wiley, New York, 1969.

Ramaswamy, V., M.-L. Chanin, J. Angell, J. Barnett, D. Gaffen, M. Gelman, P. Keckhut, Y. Koshelkov, K. Labitzke, J.-J. R. Lin, A. O’Neill, J. Nash, W. Randel, R. Rood, K. Shine, M. Shiotani, and R. Swinbank, Stratospheric temperature trends: Observations and model simulations, Rev. Geophys., 39(1), doi:10.1029/1999RG000065, 2001.

Randel, W., P. Udelhofen, E. Fleming, M. Geller, M. Gelman, K. Hamilton, D. Karoly, D. Ortland, S. Pawson, R. Swinbank, F. Wu, M. Baldwin, M.L. Chanin, P. Keckhut, K. Labitzke, E. Remsberg, A. Simmons, and D. Wu, The SPARC intercomparison of middle- atmosphere climatologies, J. Climate, 17(5), 986-1003, 2004

Russell, J. M. III, M. G. Mlynczak, L. L. Gordley, J. Tansock, and R. Esplin, An overview of the SABER experiment and preliminary calibration results, Proceedings of the SPIE, 44th Annual Meeting, Denver, Colorado, July 18-23, 3756, 277-288, 1999.

Scaife, A. A., J. R. Knight, G. K. Vallis, and C. K. Folland, A stratospheric influence on the winter NAO and North Atlantic surface climate, Geophys. Res. Lett., 32(18), L18715, doi:10.1029/2005GL023226, 2005.

Schoeberl, M. R., L. R. Lait, P. A. Newman, and J. E. Rosenfeld, The structure of the polar vortex, J. Geophys. Res., 97(D8), 7859-7882, 1992.

Senft, D. C., G. C. Papen, C. S. Gardner, J. R. Yu, D. A. Kreuger, and C. Y. She, Seasonal variations of the thermal structure of the mesopause region at Urbana, $\mathrm{IL}\left(40^{\circ} \mathrm{N}, 88^{\circ} \mathrm{W}\right)$ and Ft. Collins, $\mathrm{CO}\left(41^{\circ} \mathrm{N}, 105^{\circ} \mathrm{W}\right)$ Geophys. Res. Lett., 21(9), 821-824, 1994.

Sica, R. J., M. R. M. Izawa, K. A. Walker, C. Boone, S. V. Petelina, P. S. Argall, P. Bernath, G. B. Burns, V. Catoire, R. L. Collins, W. H. Daffer, C. De Clercq, Z. Y. Fan, B. J. Firanski, W. J. R. French, P. Gerard, M. Gerding, J. Granville, J. L. Innis, P. Keckhut, T. Kerzenmacher, A. R. Klekociuk, E. Kyrö, J. C. Lambert, E. J. Llewellyn, G. L. Manney, I. S. McDermid, K. Mizutani, Y. Murayama, C. Piccolo, P. Raspollini, M. Ridolfi, C. Robert, W. Steinbrecht, K. B. Strawbridge, K. Strong, R. Stuibi, and B. Thurairajah, Validation of the Atmospheric Chemistry Experiment (ACE) version 2.2 temperature using ground-based and space-borne measurements, Atmos. Chem. Phys., 8, 35-62, 2008.

Siskind, D. E., L. Coy, and P. Espy, Observations of stratospheric warmings and mesospheric coolings by the TIMED SABER instrument, Geophys. Res. Lett., 32, L09804, doi:110.1029/2005GL022399, 2005.

Siskind, D. E., S. D. Eckermann, L. Coy, J. P. McCormack, and C. E. Randall, On recent interannual variability of the Arctic winter mesosphere: Implications for tracer decent, Geophys. Res. Lett., 34, L09806, doi:10.1029/2007GL029293, 2007.

Solomon, S., Stratospheric ozone depletion: A review of concepts and history, Rev. Geophys., 37(3), doi:10.1029/1999RG900008, 1999.

SPARC, 2002: SPARC Intercomparison of Middle Atmosphere Climatologies, SPARC Rep. 3, 96 pp., 2002.

Wang, W., Spectral estimation of signal and noise power in Rayleigh lidar measurements of the middle atmosphere, MS Thesis, University of Alaska Fairbanks, 2003.

WMO: Scientific assessment of ozone depletion: 2006, WMO report No. 50, U. N. Environ. Program, Geneva, Switzerland, 2007.

B. Thurairajah, R. L. Collins (e-mail: rlc@gi.alaska.edu), and K. Mizuani 